Correction to Metall. Trans. A, 1991, vol. 22A, pp. 941-45

In Situ Observation of Faceted Cellular Array Growth by Dongkai Shangguan and John D. Hunt

\title{
Page 941:
}

In the second paragraph, the sentence stating "Details of the experimental work have been described elsewhere. ${ }^{[1]}$ " should read as follows:

Details of the experimental work have been described elsewhere. ${ }^{[4]}$

Correction to Metall. Trans. A, 1990, vol. 21A, pp. 2137-39

Degree of Pore-Grain Boundary Contact during Sintering

by B.R. Patterson, Y. Liu, and J.A. Griffin

\section{Page 2137:}

Equation [2] of the above paper contains an error. The correct form of Eq. [2] is

$$
\begin{aligned}
R & =\frac{2 P_{A}^{s s p}}{\left(\pi N_{L}^{s p} N_{L}^{g b}\right) /\left(1-R \cdot V_{V}^{p}\right)} \\
& =\frac{2 P_{A}^{s s p}}{\pi N_{L}^{s p} N_{L}^{g b}+2 V_{V}^{p} P_{A}^{s s p}}
\end{aligned}
$$

